\title{
Machines, Buildings, and Optimal Dynamic Taxes
}

\author{
Ctirad Slavík and Hakki Yazici*
}

February 15, 2013

\begin{abstract}
To be added.

JEL classification: E62, H21.

Keywords: Differential capital asset taxation, equipment capital, structure capital, capital-skill complementarity.
\end{abstract}

${ }^{*}$ Ctirad Slavík, Goethe University in Frankfurt, email: slavik@econ.uni-frankfurt.de, Hakki Yazici, Sabanci University in Istanbul, email: hakkiyazici@sabanciuniv.edu. We would like to thank Laurence Ales, Alex Bick, Nicola Fuchs-Schündeln, Kenichi Fukushima, Mike Golosov, Winfried Königer, Larry Jones, Yuichiro Waki, and participants at the 2012 Cologne Workshop on Macroeconomics, and the Quantitative Macro Workshop at the Goethe University in Frankfurt, and seminar participants at Oxford University and Max Planck Institute in Bonn for their comments. All remaining errors are ours. 


\section{Introduction}

The effective marginal tax rates on returns to capital assets show considerable amount of variation depending on the asset type in the U.S. corporate tax code. For instance, the effective marginal tax rate on the return to communications equipment is $19 \%$ whereas it is above $35 \%$ for non-residential buildings. ${ }^{1}$ This feature of the tax code has been the subject of a growing debate among policymakers, because it contributes to the existence of significant gaps between the effective tax rates faced by companies in different industries. President Obama recently called for a reform to abolish the tax rules that create differential taxation of capital assets in order to "level the playing field" across companies. In contrast to the extent of these policy debates, there has been little research on whether differential taxation of capital income based on capital type is a desirable feature of the tax code.

In this paper, we take a step in this direction. Our theory confirms the optimality of differential capital asset taxation, but with an important caveat. Capital assets can be divided into two groups based on the tax treatment they receive in the U.S. tax code: structures and equipment. As documented by Gravelle (2011), in the current U.S. tax code the effective tax rate on equipment capital is on average $6 \%$ below the effective tax rate on structure capital. In contrast, our theory suggests that capital equipment should be taxed at a higher rate than capital structures. We conduct a quantitative exercise to assess the quantitative importance of optimal differential capital taxation. In our baseline calibration we find that the tax rate on capital equipments should be at least $19 \%$ higher than the tax rate on structure capital.

We study dynamic optimal taxes in an economy, in which people face idiosyncratic shocks to their labor skills and the government uses capital and labor income taxes to insure people against this risk. The key feature of our environment is the capital-skill complementarity assumption in the production technology. More specifically, following Gravelle (2011) we group capital assets into two categories; structure and equipment capital. We further assume that there are two types of labor, skilled and unskilled. Following the empirical evidence in Krusell, Ohanian, Ríos-Rull, and Violante (2000), we assume that the degree of complementarity between equipment capital and skilled labor is higher than that between equipment capital and unskilled labor. Structure capital is neutral in terms of its complementarity with skilled and unskilled labor. ${ }^{2}$

Capital-skill complementarity implies that skilled and unskilled labor are not perfect substitutes and the skill premium - defined as the ratio of skilled wage to the unskilled wage -

\footnotetext{
${ }^{1}$ See Gravelle (2011) for more detailed information. Gravelle (1994) provides the details on the methodology of computing the effective tax rates.

${ }^{2}$ We do not need to make these specific assumptions on complementarity between different types of capital and skilled labor in order to conduct our theoretical analysis. We make these assumptions because we want to discipline our normative model with empirical facts.
} 
is endogenous. In particular, a decrease in the stock of equipment capital decreases the skill premium creating an indirect transfer from high skilled agents to low skilled ones. In a world in which labor taxation creates distortions, depressing the level of equipment capital creates an extra channel of redistribution or social insurance. In order to depress equipment capital accumulation, the government introduces an additional tax on its income relative to the tax on structure capital income. This implies the optimality of differential asset taxation.

Our approach to optimal dynamic taxation follows the recent New Dynamic Public Finance literature. ${ }^{3}$ We first use mechanism design theory to transform the optimal tax problem into a social planning problem and characterize its solution - the efficient allocation - analytically. Then, we provide an implementation of the efficient allocation in an incomplete market environment, in which people trade risk-free bonds. We show that in this implementation returns to equipment and structure capital are taxed differentially.

Our theory has interesting implications for labor income taxes as well. Since skilled and unskilled labor are not perfect substitutes, increasing the amount of skilled labor in the economy decreases the skill premium. As discussed above, a decrease in the skill premium creates indirect redistribution. Therefore, in order to increase skilled labor, government finds it optimal to subsidize skilled labor marginally. ${ }^{4}$

Next, we build a quantitative version of our model to assess whether the forces associated with capital-skill complementarity are quantitatively important for differential capital asset taxation. We do so in an environment with permanent skill types, in which the only role of taxation is redistribution. We find that the optimal equipment capital income tax is more than $19 \%$ higher than the tax on structure capital in the steady state, as well as along the transition path. Finally, we assess the welfare gains of switching from a tax system that implements the current U.S. differential capital taxes to one that taxes all capital types equally (Obama reform). We find that the Obama reform is welfare improving, but going all the way to the optimal tax code with higher equipment capital tax doubles the welfare gains.

The rest of the paper is structured as follows. The next section discusses the related literature in more detail. In section 3, we lay out our dynamic Mirrleesian model. In section 4 we discuss our theoretical results and in section 5 how to implement the optimal allocation in a competitive market environment. Section 6 discusses our quantitative results and section 7 concludes.

\footnotetext{
${ }^{3}$ For an excellent review of this literature, see Kocherlakota (2010).

${ }^{4}$ Stiglitz (1982) is the first paper to point out that the no distortion at the top result of static Mirrleesian taxation does not apply in environments with imperfect substitutability between skilled and unskilled labor. Our result is a generalization of his result to dynamic economies with production.
} 


\section{Related literature}

The New Dynamic Public Finance (NDPF) literature studies optimal capital and labor income taxation of households a la Mirrlees (1971) in dynamic settings in which agents' labor skills change stochastically over time. The distinguishing feature of the papers in this literature is that they do not make any assumptions about the nature of the tax system available to the government: the optimal tax system can be arbitrarily non-linear in the history of capital and labor income. In this regard, our paper is part of the growing NDPF literature. ${ }^{5}$ The main difference of this paper from the rest of the papers in this literature is that we allow for capitalskill complementarity in the production function and analyze its qualitative and quantitative implications for optimal taxes.

In this sense our paper connects the NDPF literature with the Skill Biased Technological Change (SBTC) literature which aims to explain the rise in the wage premium between skilled and unskilled workers observed in the U.S. in the last 60 years. Capital-skill complementarity has been one of the explanations that have been widely considered, see, for instance, Acemoglu (1998), He and Liu (2008) or Krusell, Ohanian, Ríos-Rull, and Violante (2000). ${ }^{6}$ This literature is mostly concerned with positive implications of capital-skill complementarity whereas we are interested in its normative consequences for optimal dynamic taxes.

Finally, our paper is related to a set of papers on optimal Mirrleesian taxation models with endogenous wages and imperfect substitutability between different types of labor. In our model, these features are direct implications of capital-skill complementarity. In contrast, Stiglitz (1982) introduces wage endogeneity to a static Mirrleesian model by assuming that labor supplies agents with different skills are not perfect substitutes. He shows that the agent with the highest income should be subsidized. In a similar setup with endogenous wages, Naito (1999) shows that uniform commodity taxation result of Atkinson and Stiglitz (1976) is no longer valid under imperfect labor substitutability. We extend the analyses of these papers to a dynamic environment and study the optimal taxation of capital as well as labor.

\footnotetext{
${ }^{5}$ Golosov, Kocherlakota, and Tsyvinski (2003) is the seminal paper in this literature. For an excellent review of the NDPF literature, see Kocherlakota (2010).

${ }^{6}$ For a review of the SBTC literature, see Violante (2008).
} 


\section{Model}

There is a continuum of measure one of agents who live for infinitely many periods. ${ }^{7}$ They differ in their skill levels: they are either born skilled or unskilled, $j \in H=\{u, s\}$. The skilled agent has productivity $z_{s}$ and the unskilled agent $z_{u}$. Their skill type evolves stochastically over their life time according to the stochastic process $\pi$. History in period $t$ is denoted by $h^{t}$, and lies in the set of all possible t period histories $H^{t}$. $\pi_{t}\left(h^{t}\right)$ is the unconditional probability of ending up at history $h^{t}$.

Production Technology. An agent of skill level $j$ in period $t$, produces $l \cdot z_{j}$ units of effective $j$ type labor when he works $l$ units. Aggregate amounts of skilled labor $L_{s}$ and unskilled labor $L_{u}$ in period $t$ are given by:

$$
\begin{aligned}
L_{s, t} & =\sum_{\left\{h^{t} \in H^{t} \mid h_{t}=s\right\}} \pi_{t}\left(h^{t}\right) l_{t}\left(h^{t}\right) z_{s} \\
L_{u, t} & =\sum_{\left\{h^{t} \in H^{t} \mid h_{t}=u\right\}} \pi_{t}\left(h^{t}\right) l_{t}\left(h^{t}\right) z_{u}
\end{aligned}
$$

We assume that there are two different occupational sectors in this economy: an unskilled sector in which only unskilled agents are allowed work and a skilled sector in which only skilled agents are allowed to work. The first assumption reflects the fact that unskilled people do not have the skills to work in the skilled sector. The second assumption can be rationalized as follows. Since a skilled agent gets the same disutility from work when working in a skilled and unskilled job, he chooses to work in the skilled sector as long as he gets a higher wage in the skilled sector (which is true in the data as well as in all our quantitative exercises). This reasoning holds in the presence of taxes under our assumption that taxes are functions of income histories only and cannot depend on skill type or occupation directly. We discuss this assumption in more detail below.

There are two different types of capital stock: structure capital $K_{s}$ and equipment capital $K_{e}$. There is a representative firm that produces the output in the economy according to the following production function:

$$
Y=\tilde{F}\left(K_{s}, K_{e}, L_{s}, L_{u}\right)
$$

where $K_{s}, K_{e}$ refer to structure capital and equipment capital, respectively. We also define a function $F$ that gives the total wealth of the economy:

$$
F=\tilde{F}+\left(1-\delta_{s}\right) K_{s}+\left(1-\delta_{e}\right) K_{e}
$$

\footnotetext{
${ }^{7}$ None of the results presented here rely on the fact that time last forever. Time can be finite as well.
} 
Wages. Given the production function $\tilde{F}$, an agent of skill history $h^{t}$ receives a wage rate $w_{t}\left(h_{t}\right)$, where

$$
\begin{aligned}
w_{t}\left(h_{t}\right) & =\frac{\partial \tilde{F}(t)}{\partial L_{s, t}} z_{s}, \text { if } h_{t}=s \\
w_{t}\left(h_{t}\right) & =\frac{\partial \tilde{F}(t)}{\partial L_{u, t}} z_{u}, \text { if } h_{t}=u
\end{aligned}
$$

Observe that the dependence of the wage rate only on current skill level and not on the whole history of skills is not by assumption but delivered endogenously by the model.

Capital-Skill Complementarity. The key feature of the technology is capital-skill complementarity which means that the degree of complementarity between equipment capital and skilled labor is higher than that between equipment capital and unskilled labor. This assumption has two important implications which make our model different from the standard model in NDPF. First, an increase in the stock of equipment capital decreases the ratio of marginal product of unskilled labor to marginal product of skilled labor. In other words, the ratio of skilled to unskilled wages is endogenous and this ratio is increasing in equipment capital. Structure capital, on the other hand, is assumed to be neutral in terms of its complementarity with skilled and unskilled labor. Second, skilled and unskilled labor are no longer perfect substitutes which implies that the skill premium is decreasing in the total amount of skilled labor and increasing in the total amount of unskilled labor. We formalize these assumptions on technology as follows.

Assumption 1. $\frac{\partial F / \partial L_{s}}{\partial F / \partial L_{u}}$ is independent of $K_{s}$.

Assumption 2. $\frac{\partial F / \partial L_{s}}{\partial F / \partial L_{u}}$ is strictly increasing in $K_{e}$.

Assumption 3. $\frac{\partial F / \partial L_{s}}{\partial F / \partial L_{u}}$ is strictly decreasing in $L_{s}$ and strictly increasing in $L_{u}$.

Preferences. All agents have the same ex-ante discounted utility function

$$
\sum_{t=1}^{\infty} \sum_{h^{t} \in H^{t}} \pi_{t}\left(h^{t}\right) \beta^{t-1}\left[u\left(c_{t}\left(h^{t}\right)\right)-v\left(l_{t}\left(h^{t}\right)\right)\right]
$$

where $\beta \in(0,1)$ is represents time discounting, and $c_{t}\left(h^{t}\right)$ and $l_{t}\left(h^{t}\right)$ represent consumption and labor at history $h^{t}$.

Allocation. An allocation is $x=\left(c_{t}\left(h^{t}\right), l_{t}\left(h^{t}\right), K_{s, t}, K_{e, t}, L_{s, t}, L_{u, t}\right)_{t=1}^{\infty}$.

Feasibility. An allocation is feasible if

$$
\sum_{h^{t} \in H^{t}} \pi_{t}\left(h^{t}\right) c_{t}\left(h^{t}\right)+K_{s, t+1}+K_{e, t+1} \leq F\left(K_{s, t}, K_{e, t}, L_{s, t}, L_{u, t}\right)
$$


and (1) and (2) hold.

Optimal Tax Problem. We allow the government to choose from a very rich set of tax instruments. Specifically, taxes are allowed to be arbitrary nonlinear functions of income histories. Following Mirrlees (1971) we do not allow taxes to depend directly on agents' skill levels, their labor supplies and the sectors they work in. One can motivate this assumption by arguing that the government cannot condition taxes on skills, labor supplies or people's sectors because they are unobservable, but none of what follows hinges on this interpretation.

However, it is convenient to use the private information assumption explicitly for technical reasons. Formally, we therefore assume that an agent's skill history, $h^{t}$, and hence his wage rate, $w_{t}\left(h^{t}\right)$, along with his labor supply $l_{t}\left(h^{t}\right)$ are private information. Income $y_{t}\left(h^{t}\right)=w_{t}\left(h_{t}\right) l_{t}\left(h^{t}\right)$ and consumption $c_{t}\left(h^{t}\right)$ are public information. Whether the agent works in the skilled or unskilled sector is also private information. This implies that when an agent wants to mimic the other type, he only has to mimic his income level. Since we assume that agents cannot switch sectors, an agent can only mimic the other type's income level by adjusting his labor hours.

Revelation Principle and Incentive-compatibility. By Revelation Principle the optimal tax problem is equivalent to a problem in which the government (planner) chooses allocations as function of agents' types subject to incentive compatibility constraints. One can think of this problem as one in which the agents report their types to the planner. The planner then assigns allocations as functions of the reports. The incentive compatibility constraints make sure that agents do not misreport their type. We now define the notion of incentive compatibility formally.

Define $\sigma_{t}: H^{t} \rightarrow\{u, s\}$. A reporting strategy is $\sigma=\left(\sigma_{t}\right)_{t=1}^{\infty} \cdot \sigma^{t}\left(h^{t}\right)=\left(\sigma_{1}\left(h^{1}\right), . ., \sigma_{t}\left(h^{t}\right)\right)$ denotes the history of reports along history $h^{t}$. The truth-telling strategy, which we denote by $\sigma^{*}$, is the one which prescribes reporting the true type at each and every node: for all $h^{t}$, $\sigma_{t}^{*}\left(h^{t}\right)=h_{t}$. Define

$$
W(\sigma \mid x)=\sum_{t=1}^{\infty} \sum_{h^{t} \in H^{t}} \pi_{t}\left(h^{t}\right) \beta^{t-1}\left[u\left(c_{t}\left(\sigma^{t}\left(h^{t}\right)\right)\right)-v\left(\frac{l_{t}\left(\sigma^{t}\left(h^{t}\right)\right) w_{t}\left(\sigma_{t}\left(h^{t}\right)\right)}{w_{t}\left(h_{t}\right)}\right)\right] .
$$

as the expected discounted value of using reporting strategy $\sigma$ given an allocation $x$.

An allocation is incentive-compatible if

$$
W\left(\sigma^{*} \mid x\right) \geq W(\sigma \mid x)
$$

Simplifying the Incentive Constraints. Following Fernandes and Phelan (2000), without loss of generality, we restrict attention to the set of reporting strategies that has lying only at a single node. ${ }^{8}$ This allows us to replace (5) with a sequence of temporary incentive constraints,

\footnotetext{
${ }^{8}$ Temporary incentive constraints are first shown to be necessary and sufficient by Green (1987) in the context
} 
one for each node.

An allocation $x$ is incentive compatible if and only if at each node $h^{t-1}$ and for all $h_{t} \in H$,

$$
\begin{gathered}
u\left(c_{t}\left(h^{t-1}, h_{t}\right)\right)-v\left(l_{t}\left(h^{t-1}, h_{t}\right)\right)+\sum_{m=t+1}^{\infty} \sum_{\left\{h^{m} \in H^{m} \mid h^{m} \succ h^{t}\right\}} \pi_{m}\left(h^{m}\right) \beta^{m-t}\left[u\left(c_{m}\left(h^{m}\right)\right)-v\left(l_{m}\left(h^{m}\right)\right)\right] \\
\geq u\left(c_{t}\left(h^{t-1}, h_{t}^{o}\right)\right)-v\left(\frac{l_{t}\left(h^{t-1}, h_{t}^{o}\right) w_{t}\left(h^{t-1}, h_{t}^{o}\right)}{w_{t}\left(h^{t-1}, h_{t}\right)}\right) \\
+\sum_{m=t+1}^{\infty} \sum_{\left\{h^{m} \in H^{m} \mid h^{m} \succ h^{t}\right\}} \pi_{m}\left(h^{m}\right) \beta^{m-t}\left[u\left(c_{m}\left(\tilde{h}^{m}\right)\right)-v\left(l_{m}\left(\tilde{h}^{m}\right)\right)\right]
\end{gathered}
$$

where $h_{t}^{o}$ is the complement of $h_{t}$ in the set $H$ and $\tilde{h}^{m}=\left(h^{t-1}, h_{t}^{o}, h_{t+1}, . ., h_{m}\right)$.

In the rest of the paper, we use (6) to represent incentive-compatibility.

The Social Planning Problem. The social planning problem that defines the efficient allocation is:

$$
\max _{x} \sum_{t=1}^{\infty} \sum_{h^{t} \in H^{t}} \pi_{t}\left(h^{t}\right) \beta^{t-1}\left[u\left(c_{t}\left(h^{t}\right)\right)-v\left(l_{t}\left(h^{t}\right)\right)\right]
$$

subject to

$$
K_{s, 1}, K_{e, 1}>0 \text { given and }
$$

$(1),(2),(3),(4)$ and $(6)$.

The allocation that solves the social planning problem is called the efficient allocation and is denoted with a star.

\section{Characterization of the Efficient Allocation}

For any allocation $x$, define the following three wedges.

1. The capital return wedge measures the distortions in capital accumulation decision of the two types of capital by comparing their physical marginal returns:

$$
\tau_{E}(t)=\frac{F_{2}\left(K_{s, t}, K_{e, t}, L_{s, t}, L_{u, t}\right)}{F_{1}\left(K_{s, t}, K_{e, t}, L_{s, t}, L_{u, t}\right)}-1
$$

of a dynamic moral hazard problem where people face i.i.d. endowment shocks that are private information. Fernandes and Phelan (2000) generalized this result to environments with persistent private shocks. To be precise, we need to use two more assumptions to be able to use temporary incentive constraints. First, we need that each possible skill history is reached with strictly positive probability. Second, we need a transversality condition which we get if we assume that instantaneous utility is bounded. 
2. The intertemporal wedge measures the distortions in intertemporal allocation of consumption by comparing the intertemporal marginal rate of substitution to the marginal rate of transformation through two capital stocks:

$$
\tau_{K, i}\left(h^{t}\right)=1-\frac{u^{\prime}\left(c_{t}\left(h^{t}\right)\right)}{\beta F_{i, t+1} E_{t}\left\{u^{\prime}\left(c_{t+1}\left(h^{t+1}\right)\right) \mid h^{t}\right\}} .
$$

3. The intratemporal wedge measures the distortions in consumption labor decision by comparing the marginal rate of substitution between consumption and labor to the marginal product of labor:

$$
\tau_{Y}\left(h^{t}\right)=1-\frac{v^{\prime}\left(l_{t}\left(h^{t}\right)\right)}{w_{t}\left(h^{t}\right) u^{\prime}\left(c_{t}\left(h^{t}\right)\right)} .
$$

In this section, we characterize the efficient allocation along these three wedges.

\subsection{Capital Return Wedge}

In the standard two sector growth model, a given level of aggregate savings is allocated between the two types of capital to equate their physical marginal returns. The proposition below shows that in the efficient allocation, this is not true, meaning it is optimal to create a wedge between the physical returns to two types of capital.

Proposition 1. In the efficient allocation, in any period $t \geq 2$ :

$$
F_{1}\left(K_{s, t}^{*}, K_{e, t}^{*}, L_{s, t}^{*}, L_{u, t}^{*}\right)=F_{2}\left(K_{s, t}^{*}, K_{e, t}^{*}, L_{s, t}^{*}, L_{u, t}^{*}\right)+\frac{1}{\lambda_{t}^{*}} X_{t}^{*}
$$

where

$$
X_{t}^{*}=\sum_{\left\{h^{t} \in H^{t}\right\}} \mu_{t}^{*}\left(h^{t}\right) v^{\prime}\left(\frac{l_{t}^{*}\left(h^{t-1}, h_{t}^{o}\right) w_{t}\left(h^{t-1}, h_{t}^{o}\right)}{w_{t}\left(h^{t-1}, h_{t}\right)}\right) l_{t}^{*}\left(h^{t-1}, h_{t}^{o}\right) \frac{\partial \frac{w_{t}\left(h^{t-1}, h_{t}^{o}\right)}{w_{t}\left(h^{t-1}, h_{t}\right)}}{\partial K_{e, t}^{*}}
$$

and $\lambda_{t}$ and $\mu_{t}\left(h^{t}\right)$ are Lagrange multipliers on period $t$ feasibility constraint and the incentive constraint at history $h^{t}$.

Proof. Under Assumptions 1 and 2, the result follows from the FOCs with respect to two capital types

$$
\begin{gathered}
\left(K_{s, t}\right):-\lambda_{t-1}^{*}+\lambda_{t}^{*} F_{1}\left(K_{s, t}^{*}, K_{e, t}^{*}, L_{s, t}^{*}, L_{u, t}^{*}\right)=0, \\
\left(K_{e, t}\right):-\lambda_{t-1}^{*}+\lambda_{t}^{*} F_{2}\left(K_{s, t}^{*}, K_{e, t}^{*}, L_{s, t}^{*}, L_{u, t}^{*}\right) \\
+\sum_{\left\{h^{t} \in H^{t}\right\}} \mu_{t}^{*}\left(h^{t}\right) v^{\prime}\left(\frac{l_{t}^{*}\left(h^{t-1}, h_{t}^{o}\right) w_{t}\left(h^{t-1}, h_{t}^{o}\right)}{w_{t}\left(h^{t-1}, h_{t}\right)}\right) l_{t}^{*}\left(h^{t-1}, h_{t}^{o}\right) \frac{\partial \frac{w_{t}\left(h^{t-1}, h_{t}^{o}\right)}{w_{t}\left(h^{t-1}, h_{t}\right)}}{\partial K_{e, t}^{*}}=0 .
\end{gathered}
$$


The intuition behind this result is simple. Due to capital-skill complementarity, increasing the level of equipment capital in a given period increases the wage premium in that period and hence affects the incentive constraints. From a planning perspective, this means increasing equipment capital has an extra marginal return, $\frac{1}{\lambda_{t}^{*}} X_{t}^{*}$, in addition to the physical return, $F_{2, t}$. Since structure capital is neutral, changing its level does not affect the incentive constraints, and hence the only return to it is the physical return, $F_{1, t}$. The proposition then just collects the total return to equipment capital and equates that to the return from structure capital.

Observe that the capital-skill complementarity assumption is key in the sense that if there was no complementarity, it would be efficient to equate the physical marginal returns to the two types of capital. The private information assumption on skills is also important: if the planner knows people's types, then there are no incentive constraints and hence $X_{t}^{*}=0$, and we would be back to the zero capital return wedge.

Corollary 1. In any period $t \geq 2$, the efficient capital return wedge is given by

$$
\tau_{E}^{*}(t)=\frac{F_{2}\left(K_{s, t}^{*}, K_{e, t}^{*}, L_{s, t}^{*}, L_{u, t}^{*}\right)}{F_{2}\left(K_{s, t}^{*}, K_{e, t}^{*}, L_{s, t}^{*}, L_{u, t}^{*}\right)+\frac{1}{\lambda_{t}^{*}} X_{t}^{*}}-1
$$

This wedge can be interpreted as an implicit tax on equipment capital. To understand better, suppose for the sake of argument that $\frac{1}{\lambda_{t}^{*}} X_{t}^{*}<0$. In this case the corollary above calls for an implicit tax on equipment capital, $\tau_{E}^{*}(t)>0$. The intuition is as follows. Remember that

$\frac{1}{\lambda_{t}^{*}} X_{t}^{*}$ measures the incentive effect of increasing equipment capital. Therefore, $\frac{1}{\lambda_{t}^{*}} X_{t}^{*}<0$ means increasing equipment capital creates incentive costs, which implies it is efficient to discourage investment in equipment capital relative to structure capital, suggesting a tax.

\subsection{Intertemporal Wedges}

Now we provide two related intertemporal characterizations of the efficient allocation.

Proposition 2. Following any history $h^{t}$, we have

$$
\frac{1}{u^{\prime}\left(c_{t}^{*}\left(h^{t}\right)\right)}=\frac{1}{\beta F_{1, t+1}^{*}} E_{t}\left\{\frac{1}{u^{\prime}\left(c_{t+1}^{*}\left(h^{t+1}\right)\right)} \mid h^{t}\right\}
$$

and

$$
\frac{1}{u^{\prime}\left(c_{t}^{*}\left(h^{t}\right)\right)}=\frac{1}{\beta\left(F_{2, t+1}^{*}+X_{t+1}^{*} / \lambda_{t+1}^{*}\right)} E_{t}\left\{\frac{1}{u^{\prime}\left(c_{t+1}^{*}\left(h^{t+1}\right)\right)} \mid h^{t}\right\} .
$$

Proof. Under Assumption 1, equation (9) follows directly from Golosov, Kocherlakota, and Tsyvinski (2003). Equation (10) is then implied by Proposition 1. 
Equation (9) describes the efficient way of allocating consumption across two consecutive periods using structure capital, and is the standard inverse Euler equation derived by Rogerson (1985) and Golosov, Kocherlakota, and Tsyvinski (2003). The intuition behind it is the following. The left-hand-side of (9) gives how much resources are saved by decreasing period $t$ utility by one unit at node $h^{t}$. The right-hand-side is the period $t$ resource cost of increasing utility by $1 / \beta$ units in both contingencies in period $t+1$. These values have to be equal in the efficient allocation. Otherwise by increasing or decreasing (depending on the direction of the inequality) savings at node $h^{t}$ the planner could provide the same welfare to the individual in an incentive compatible way at a lower total cost. That would contradict with the efficiency of the original allocation.

Observe that we use $F_{1, t+1}^{*}$ when discounting the period $t+1$ cost of increasing period $t+1$ utility to period $t$ because here the planner is using the level of $K_{s, t+1}$ to transfer resources between periods. This is the key difference between the first and second conditions of the proposition. In the second condition, (10), again the planner is comparing period $t$ and $t+1$ costs of increasing agents utility by one unit. However, now resources are transferred between periods using $K_{e, t+1}$, and there is an additional incentive cost (or benefit depending on which incentive constraints bind) of changing the level of $K_{e, t+1}$, which is equal to $X_{t+1}^{*} / \lambda_{t+1}^{*}$, that is reflected in the overall marginal return of equipment capital, $\left(F_{2, t+1}^{*}+X_{t+1}^{*} / \lambda_{t+1}^{*}\right)$.

Corollary 2. The implicit tax on structure and equipment capital are given by the following expressions, respectively:

$\tau_{K, s}^{*}\left(h^{t}\right)=\frac{\left[\prod_{j} \pi_{t+1}\left(h^{t}, j \mid h^{t}\right)\right] \cdot\left[u^{\prime}\left(c_{t+1}^{*}\left(h^{t}, s\right)\right)-u^{\prime}\left(c_{t+1}^{*}\left(h^{t}, u\right)\right)\right]^{2}}{u^{\prime}\left(c_{t+1}^{*}\left(h^{t}, s\right)\right) u^{\prime}\left(c_{t+1}^{*}\left(h^{t}, u\right)\right)+\left[\prod_{j} \pi_{t+1}\left(h^{t}, j \mid h^{t}\right)\right] \cdot\left[u^{\prime}\left(c_{t+1}^{*}\left(h^{t}, s\right)\right)-u^{\prime}\left(c_{t+1}^{*}\left(h^{t}, u\right)\right)\right]^{2}}>0$,

and

$$
\left[1-\tau_{K, e}^{*}\left(h^{t}\right)\right]=\frac{\left(F_{2, t+1}^{*}+X_{t+1}^{*} / \lambda_{t+1}^{*}\right)}{F_{2, t+1}^{*}}\left[1-\tau_{K, s}^{*}\left(h^{t}\right)\right] .
$$

The corollary above has two parts. The first part is standard in the NDPF literature and says that the intertemporal wedge regarding structure capital is positive. This means that if we allow the agent to borrow and save at the marginal rate of return to structure capital, she would save beyond the efficient level and work less than socially efficient level if she turns out to be of skilled type. To prevent this, we need to discourage savings which can be interpreted as an implicit tax on investment in structure capital. To understand the second part, assume that $X_{t+1}^{*} / \lambda_{t+1}^{*}<0$. That implies $\tau_{K, e}^{*}\left(h^{t}\right)>\tau_{K, s}^{*}\left(h^{t}\right)$, meaning the implicit tax on equipment capital 
should be higher than that on structure capital. This is because the agent has the same motive for oversaving relative to the efficient allocation, but when this saving is carried out through investment in equipment capital, this has an additional incentive cost to society of $X_{t+1}^{*} / \lambda_{t+1}^{*}$. Therefore, equipment capital investment should be discouraged even more.

Differences in capital prices. One explanation for the increasing use of equipment capital observed in the data is that the relative price of equipment capital is lower that one and decreasing. It is straightforward to extend the results of the previous 2 sections to account for this possibility. We do just that in appendix A and explore some of the implications this has for optimal taxation quantitatively in section 6 .

\subsection{The Relevant Case}

We now impose two natural assumptions that make it possible to proceed further with our characterization results. In particular, we are able to sign the capital return wedge and determine whether the intertemporal wedge is higher for structure or equipment capital. The first assumption concerns the wages of the two types of labor, the second the pattern of binding incentive constraints.

Since wages are endogenous in our model, it is possible that skilled agents earn a lower wage rate than unskilled agents in a certain period (e.g. if the level of equipment capital is low). However, this is not the empirically relevant case and it does not happen in our quantitative exercises. In what follows we will assume that in any period skilled workers earn higher wages than unskilled workers.

Assumption 4. In any period $t, w_{t}(s)>w_{t}(u)$.

As far as we know, there is no result that establishes the pattern of binding incentive constraints for a general skill process in our environment. However, in all the quantitative exercises we conduct in section 5 only the downward incentive constraints bind. ${ }^{9}$ We find it useful to formalize this pattern with the following assumption.

Assumption 5. Suppose only downward IC's bind. ${ }^{10}$

\footnotetext{
${ }^{9}$ By downward incentive constraints, we mean those that prevent the skilled agent from pretending to be the unskilled agent.

${ }^{10}$ One can establish that this is the pattern of the binding incentive constraints when skills are i.i.d. and utility function satisfies single crossing property which is automatically satisfied in our environment with preferences separable between consumption and labor. With skill persistence, however, one can construct examples in which some of the upward incentive constraints bind.
} 
Lemma 1. Suppose Assumptions 3 and 4 hold. Then,

$$
X_{t+1}^{*}<0
$$

Proof. Under Assumptions 3 and 4,

$$
X_{t+1}^{*}=\sum_{\left\{h^{t} \in H^{t}\right\}} \mu_{t+1}^{*}\left(s \mid h^{t}\right) v^{\prime}\left(\frac{l_{t+1}^{*}\left(h^{t}, u\right) w_{t+1}\left(h^{t}, u\right)}{w_{t+1}\left(h^{t}, s\right)}\right) l_{t+1}^{*}\left(h^{t}, u\right) \frac{\partial \frac{w_{t+1}\left(h^{t}, u\right)}{w_{t+1}\left(h^{t}, s\right)}}{\partial K_{e, t+1}^{*}} .
$$

Under Assumption 2, we have

$$
\frac{\partial \frac{w_{t+1}\left(h^{t}, u\right)}{w_{t+1}\left(h^{t}, s\right)}}{\partial K_{e, t+1}}=\frac{\partial \frac{\frac{\partial F_{t+1}}{\partial L_{u, t+1}} z_{t}(u)}{\partial F_{t+1}} z_{t}(s)}{\partial K_{e, t+1}}<0
$$

implying the result.

Remember that $X_{t+1}^{*}$ represents the effect of increasing equipment capital on the incentives. By Assumption 2, we know that increasing equipment capital in period $t$ increases the wage premium in that period thereby tightening the incentive constraints that people who are skilled in period $t$ face and relaxing those that people who are unskilled in period $t$. By Assumption 4 above, incentive constraints that unskilled face are already slack, implying the only effect of increasing equipment capital is tightening the incentive constraints of the period $t$ skilled. Hence, the total effect of increasing $K_{e}$ on incentives is negative.

Proposition 3. Under Assumptions 3 and 4, for $t \geq 2$

$$
\tau_{E}^{*}(t)>0
$$

Or equivalently,

$$
\tau_{K, e}^{*}\left(h^{t}\right)>\tau_{K, s}^{*}\left(h^{t}\right)
$$

The first part of this proposition says that the physical return on structure capital should be higher than the physical return on equipment capital. This is intuitive: equipment capital has an extra incentive cost relative to the structure capital, and hence, it is optimal to invest less in it which implies its marginal physical return is going to be higher since there is diminishing marginal returns to both types of capital. Another way of reading this result is that we need to tax equipment capital in order to create this positive wedge between the marginal returns to structure and equipment capital. The second part of the proposition says that the intertemporal wedge is higher for equipment capital than it is for structure capital. The intuition behind this result is that when people save through equipment capital they do not take into account 
the adverse effect of increasing equipment capital on the wage ratio and hence on incentives. Therefore, they have a tendency to save too much through equipment capital compared to structure capital and therefore investment in equipment capital should be taxes more.

\subsection{Intratemporal Wedges}

The famous no distortion at the top result proven originally by Sadka (1976) and Seade (1977) states that in a static Mirrleesian economy, if the distribution of skills has a finite support, then the consumption labor decision of the agent with the highest skill level should not be distorted. A counterpart of this proposition holds in a standard dynamic Mirrleesian model with discrete skill types: in any period, an agent who is currently of the highest skill level should face zero implicit marginal labor tax. This result does not depend on the stochastic process governing skills but requires that only the downward incentive constraints bind. ${ }^{11}$

In this section we show that the no distortion at the top result does not hold when there is capital-skill complementarity even if only the downward constraints bind. This result is in line with Stiglitz (1982), who shows that when two types of labor are imperfect substitutes then the top agents' labor supply decision should be distorted. ${ }^{12}$ In particular Stiglitz shows that the top income agents' labor should be subsidized. The intuition is that increasing the labor supply of the skilled agents decreases the wage ratio of the skilled relative to unskilled agents reducing the bite of the incentive problem. With capital-skill complementarity in the production function, skilled and unskilled labor become imperfect substitutes, and hence Stiglitz (1982) result is generalized to dynamic economies with capital accumulation. ${ }^{13}$

Proposition 4. Suppose Assumptions 3 and 4 hold. In any period t, the implicit labor tax on the agent who is currently skilled is negative.

Proof. Let for any $t, \bar{h}^{t}=\left(h^{t-1}, s\right)$ and for $m \leq t, \bar{h}^{m}$ be the predecessor in period $m$. Consider the first order optimality conditions with respect to $c_{t}\left(\bar{h}^{t}\right)$ and $l_{t}\left(\bar{h}^{t}\right)$ :

$$
\begin{aligned}
u^{\prime}\left(c_{t}\left(\bar{h}^{t}\right)\right)\left(\beta^{t-1} \pi_{t}\left(\bar{h}^{t}\right)+\sum_{m=1}^{t} \beta^{t-m} \pi_{t}\left(\bar{h}^{t} \mid \bar{h}^{m}\right) \mu_{m}\left(\bar{h}^{m}\right)\left[\chi_{\{s\}}\left(\bar{h}_{m}\right)-\chi_{\{u\}}\left(\bar{h}_{m}\right)\right]\right) & =\lambda_{t} \pi_{t}\left(\bar{h}^{t}\right) \\
v^{\prime}\left(l_{t}\left(\bar{h}^{t}\right)\right)\left(\beta^{t-1} \pi_{t}\left(\bar{h}^{t}\right)+\beta^{t-m} \pi_{t}\left(\bar{h}^{t} \mid \bar{h}^{m}\right) \mu_{m}\left(\bar{h}^{m}\right)\left[\chi_{\{s\}}\left(\bar{h}_{m}\right)-\chi_{\{u\}}\left(\bar{h}_{m}\right)\right]-\frac{Y_{t} \pi_{t}\left(\bar{h}^{t}\right)}{v^{\prime}\left(l_{t}\left(\bar{h}^{t}\right)\right)}\right) & =\lambda_{t} w_{t}\left(\bar{h}^{t}\right) \pi_{t}\left(\bar{h}^{t}\right),
\end{aligned}
$$

\footnotetext{
${ }^{11}$ Farhi and Werning (2012) and Golosov, Troshkin, and Tsyvinski (2011) prove this result for dynamic economies with continuous support under certain assumptions on the primitives.

${ }^{12}$ Rotschild and Scheuer (2012) generalize Stiglitz's result to an economy with occupational choice and a continuum of types.

${ }^{13}$ In a finite dynamic Mirrleesian economy under full persistence in innate skills and human capital accumulation, Grochulski and Piskorski (2010) also prove that the no distortion at the top result does not hold in all but the last period.
} 
where $\chi$ is the indicator function and

$$
Y_{t}=\sum_{\left\{h^{t} \in H^{t} \mid h_{t}=s\right\}} \mu_{t}^{*}\left(h^{t}\right) v^{\prime}\left(\frac{l_{t}^{*}\left(h^{t-1}, u\right) w_{t}\left(h^{t-1}, u\right)}{w_{t}\left(h^{t-1}, s\right)}\right) l_{t}^{*}\left(h^{t-1}, u\right) \frac{\partial \frac{w_{t}\left(h^{t-1}, u\right)}{w_{t}\left(h^{t-1}, s\right)}}{\partial l_{t}^{*}\left(\bar{h}^{t}\right)} z_{s}>0
$$

since capital-skill complementarity implies $\frac{\partial \frac{w_{t}\left(h^{t-1}, u\right)}{w_{t}\left(h^{t-1}, s\right)}}{\partial l_{t}^{*}\left(h^{t}\right)}>0$.

Then,

$$
\tau_{t}^{\text {intra }}\left(\bar{h}^{t}\right)=1-\frac{\left(\beta^{t-1} \pi_{t}\left(\bar{h}^{t}\right)+\sum_{m=1}^{t} \mu_{m}\left(\bar{h}^{m}\right) \pi_{t}\left(\bar{h}^{t} \mid \bar{h}^{m}\right)\right)}{\left(\beta^{t-1} \pi_{t}\left(\bar{h}^{t}\right)+\sum_{m=1}^{t} \mu_{m}\left(\bar{h}^{m}\right) \pi_{t}\left(\bar{h}^{t} \mid \bar{h}^{m}\right)-\frac{Y_{t}\left(\bar{h}^{t}\right)}{v^{\prime}\left(l_{t}\left(\bar{h}^{t}\right)\right)}\right)}<0 .
$$

Remark 1. Observe that in a standard dynamic Mirrleesian economy in which the two types of capital are perfect substitutes, $Y_{t}=0$. Therefore, we recover a dynamic version of the no distortion at the top result: people face zero implicit labor tax in all periods in which they are skilled.

\section{Implementation}

In this section we consider the design of optimal tax systems that implement efficient allocation in a setting where agents trade in decentralized markets. An optimal tax system implements the efficient allocation in a market if the efficient allocation arises as an equilibrium of this market arrangement under the tax system. Therefore, optimal tax systems depend on the given market structure. Here we focus on an incomplete market environment where incompleteness refers to the assumption that people are not allowed to trade state-contingent claims to future consumption, and provide two different optimal tax systems both of which implement the efficient allocation.

We begin by describing the market arrangement and the notion of equilibrium in the presence of taxes. There is a single representative firm that owns the technology of production. The firm rents structure and equipment capital and hires labor taking rental rates $r_{s, t}$ and $r_{e, t}$ and wage rates for skilled and unskilled $w_{s, t}$ and $w_{u, t}$ as given. At the beginning of the economy all agents are endowed with $K_{s, 1}^{*}$ and $K_{e, 1}^{*}$ units of capital. They trade equipment and structure capital, labor, and consumption in sequential competitive markets. There is a government that can tax consumers and firms in any arbitrarily non-linear and history dependent way. The only restriction on the set of taxes is that the tax code cannot depend on agent's skill histories. ${ }^{14}$

\footnotetext{
${ }^{14}$ We can motivate this restriction a la Mirrlees (1971) by assuming that skill types are private information to the agents themselves, but this is not crucial as none of the discussion that follows depends on this interpretation.
} 
Taxes. Following Kocherlakota (2005), the tax on consumers is specified as follows. Let $\tau_{t}^{y}: \mathbb{R}_{+}^{t} \rightarrow \mathbb{R}$ denote the labor tax schedule, where $\tau_{t}^{y}\left(y^{t}\right)$ is the labor income tax an agent with an income history $y^{t}=y_{1}, \ldots, y_{t}$ pays in period $t$. There are also linear taxes on people's holdings of structure and equipment capital which may depend on their income history. Letting $\tau_{t}^{s}, \tau_{t}^{e}: \mathbb{R}_{+}^{t} \rightarrow \mathbb{R}$ denote linear tax rates on holdings of structure and equipment capital, an agent with income history $y^{t}$ pays $\tau_{t}^{s}\left(y^{t}\right)\left(1-\delta_{s}+r_{s, t}\right) k_{s, t}\left(h^{t-1}\right)+\tau_{t}^{e}\left(y^{t}\right)\left(1-\delta_{e}+r_{e, t}\right) k_{e, t}\left(h^{t-1}\right)$, where $k_{i, t}\left(h^{t-1}\right)$ denotes agent's holdings of wealth in terms of capital type $i$. There are two differences compared to Kocherlakota (2005) in terms of the set of taxes government is allowed to use. First, in our environment households carry wealth over time using the two types of capital, and at the outset we allow the taxes on wealth to depend on which sector the capital is invested in. Second, government also has access to linear history independent tax on firm's equipment capital payments, denoted by $\tau_{t}^{f}: \mathbb{R}_{+} \rightarrow \mathbb{R}$.

Consumer's problem. Taking prices $(r, w)$ and taxes $\left(\tau^{y}, \tau^{s}, \tau^{e}\right)$ as given, consumers solve

$$
\max _{c, y, k_{s}, k_{e}} \sum_{t=1}^{\infty} \sum_{h^{t} \in H^{t}} \pi_{t}\left(h^{t}\right) \beta^{t-1}\left[u\left(c_{t}\left(h^{t}\right)\right)-v\left(\frac{y_{t}\left(h^{t}\right)}{w_{t}\left(h^{t}\right)}\right)\right]
$$

subject to

$$
\begin{gathered}
c_{t}\left(h^{t}\right)+k_{s, t+1}\left(h^{t}\right)+k_{e, t+1}\left(h^{t}\right) \leq y_{t}\left(h^{t}\right)-\tau_{t}^{y}\left(y^{t}\left(h^{t}\right)\right) \\
+\left[1-\tau_{t}^{s}\left(y^{t}\left(h^{t}\right)\right)\right]\left(1-\delta_{s}+r_{s, t}\right) k_{s, t}\left(h^{t-1}\right) \\
+\left[1-\tau_{t}^{e}\left(y^{t}\left(h^{t}\right)\right)\right]\left(1-\delta_{e}+r_{e, t}\right) k_{e, t}\left(h^{t-1}\right), \\
k_{s, 1} \leq K_{s, 1}^{*}, k_{e, 1} \leq K_{e, 1}^{*}, \\
c, y, k_{s}, k_{e} \text { is nonnegative. }
\end{gathered}
$$

Firm's problem. Taking $(r, w)$ and $\tau^{f}$ as given, the firm solves

$$
\max _{K_{e, t}, K_{s, t} L_{s, t}, L_{u, t}} \tilde{F}\left(K_{s, t}, K_{e, t}, L_{s, t}, L_{u, t}\right)-r_{s, t} K_{s, t}-\left(1+\tau_{t}^{f}\right) r_{e, t} K_{e, t}-\frac{w_{s, t}}{z_{t}(s)} L_{s, t}-\frac{w_{u, t}}{z_{t}(u)} L_{u, t} .
$$

Equilibrium. Given a tax system $\left(\tau_{t}^{y}, \tau_{t}^{s}, \tau_{t}^{e}, \tau_{t}^{f}\right)_{t=1}^{\infty}$, an equilibrium is an allocation for consumers, $\left(c_{t}, y_{t}, k_{s, t}, k_{e, t}\right)_{t=1}^{\infty}$, an allocation for the firm, $\left(K_{s, t}, K_{e, t}, L_{s, t}, L_{u, t}\right)_{t=1}^{\infty}$, and prices $\left(r_{t}, w_{t}\right)_{t=1}^{\infty}$ such that $\left(c_{t}, y_{t}, k_{s, t}, k_{e, t}\right)_{t=1}^{\infty}$ solves consumer's problem, $\left(K_{s, t}, K_{e, t}, L_{s, t}, L_{u, t}\right)_{t=1}^{\infty}$ solves 
firm's problem, and markets clear:

$$
\begin{aligned}
\sum_{h^{t} \in H^{t}} \pi_{t}\left(h^{t}\right) c_{t}\left(h^{t}\right)+K_{s, t+1}+K_{e, t+1}=F\left(K_{s, t}, K_{e, t}, L_{s, t}, L_{u, t}\right), \\
K_{s, t}=\sum_{h^{t} \in H^{t}} \pi_{t}\left(h^{t}\right) k_{s, t}\left(h^{t}\right), \\
K_{e, t}=\sum_{h^{t} \in H^{t}} \pi_{t}\left(h^{t}\right) k_{e, t}\left(h^{t}\right), \\
L_{s, t}=\sum_{\left\{h^{t} \in H^{t} \mid h_{t}=s\right\}} \pi_{t}\left(h^{t}\right) \frac{y_{t}\left(h^{t}\right)}{w_{s, t}} z_{s} \\
L_{u, t}=\sum_{\left\{h^{t} \in H^{t} \mid h_{t}=u\right\}} \pi_{t}\left(h^{t}\right) \frac{y_{t}\left(h^{t}\right)}{w_{u, t}} z_{u} .
\end{aligned}
$$

Note that the government's period by period budget balance is implied by Walras' Law:

$\sum_{h^{t} \in H^{t}} \pi_{t}\left(h^{t}\right)\left[\tau_{t}^{s}\left(y^{t}\left(h^{t}\right)\right)\left(1-\delta_{s}+r_{s, t}\right) k_{s, t}\left(h^{t-1}\right)+\tau_{t}^{e}\left(y^{t}\left(h^{t}\right)\right)\left(1-\delta_{e}+r_{e, t}\right) k_{e, t}\left(h^{t-1}\right)+\tau_{t}^{y}\left(y^{t}\left(h^{t}\right)\right)\right]=0$.

In what follows we describe two optimal tax systems and show that they implement the efficient allocation in the market setup described above. Before doing so, we provide a formal definition of our notion of implementation.

Implementation. A tax system $\left(\tau_{t}^{y}, \tau_{t}^{s}, \tau_{t}^{e}, \tau_{t}^{f}\right)_{t=1}^{\infty}$ implements the efficient allocation

$\left(c_{t}^{*}, l_{t}^{*}, K_{s, t}^{*}, K_{e, t}^{*}, L_{s, t}^{*}, L_{u, t}^{*}\right)_{t=1}^{\infty}$ if an allocation for consumers $\left(c_{t}^{*}, y_{t}^{*}, k_{s, t}, k_{e, t}\right)_{t=1}^{\infty}$ and allocation for the firm $\left(K_{s, t}^{*}, K_{e, t}^{*}, L_{s, t}^{*}, L_{u, t}^{*}\right)_{t=1}^{\infty}$ jointly with the tax system and prices $\left(r_{t}, w_{t}\right)_{t=1}^{\infty}$ constitute an equilibrium.

\subsection{Optimal Tax System 1: A Case for Differential Asset Taxation}

Now we are ready to provide the first of the two implementations. First, we construct the optimal tax system; then we prove that it implements the efficient allocation. Finally, we characterize some of its properties.

Optimal Tax System 1. We begin by describing optimal capital taxes. Set capital taxes 
such that, for $i=s, e$

$$
\begin{aligned}
\tau_{t+1}^{i *}\left(y^{t+1}\right) & =1-\frac{u^{\prime}\left(c_{t}^{*}\left(h^{t}\right)\right)}{\beta u^{\prime}\left(c_{t+1}^{*}\left(h^{t+1}\right)\right)\left(1-\delta_{i}+r_{i, t+1}\right)}, \text { if } y^{t+1} \in Y^{t+1 *} \\
\tau_{t+1}^{i *}\left(y^{t+1}\right) & =1, \text { if else, }
\end{aligned}
$$

where $Y^{t *} \equiv\left\{y^{t}: y^{t}=y^{t *}\left(h^{t}\right), h^{t} \in H^{t}\right\}, y^{t *}\left(h^{t}\right) \equiv\left(y_{t}^{*}\left(h^{t}\right)\right)_{m=1}^{t}, y_{t}^{*}\left(h^{t-1}, j\right)=M P L_{j, t}^{*} z_{j} l_{t}^{*}\left(h^{t-1}, j\right)$ for each $j$, and $M P L_{j, t}^{*}=\frac{\partial \tilde{F}_{1}\left(K_{s, t}^{*}, K_{e, t}^{*}, L_{s, t}^{*}, L_{u, t}^{*}\right)}{\partial L_{j, t}}$. In words, $Y^{t *}$ is the set of labor income histories observed in the efficient allocation. Set labor income taxes such that if $y^{t} \in Y^{t *}$, then $\tau_{t}^{y *}\left(y^{t}\right)$ and $k_{s, t+1}^{*}\left(h^{t}\right), k_{e, t+1}^{*}\left(h^{t}\right)$ are defined to satisfy the flow budget constraints every period

$$
\begin{aligned}
c_{t}^{*}\left(h^{t}\right)+k_{s, t+1}^{*}\left(h^{t}\right)+k_{e, t+1}^{*}\left(h^{t}\right)= & y_{t}^{*}\left(h^{t}\right)-\tau_{t}^{y *}\left(y^{t}\right) \\
& +\left[1-\tau_{t}^{s *}\left(y^{t}\right)\right]\left(1-\delta_{s}+M P K_{s, t}^{*}\right) k_{s, t}^{*}\left(h^{t-1}\right) \\
& +\left[1-\tau_{t}^{e *}\left(y^{t}\right)\right]\left(1-\delta_{e}+M P K_{e, t}^{*}\right) k_{e, t}^{*}\left(h^{t-1}\right),
\end{aligned}
$$

where

$$
\begin{aligned}
M P K_{s, t}^{*} & =\tilde{F}_{1}\left(K_{s, t}^{*}, K_{e, t}^{*}, L_{s, t}^{*}, L_{u, t}^{*}\right), \\
M P K_{e, t}^{*} & =\tilde{F}_{2}\left(K_{s, t}^{*}, K_{e, t}^{*}, L_{s, t}^{*}, L_{u, t}^{*}\right) .
\end{aligned}
$$

If $y^{t} \notin Y^{t *}$, then

$$
\tau_{t}^{y *}\left(y^{t}\right)=2 y_{t}
$$

Finally, set

$$
\tau_{t}^{f *}=0
$$

Proposition 5. Optimal Tax System 1 implements the efficient allocation.

Proof. First, define prices as $r_{s, t}^{*}=M P K_{s, t}^{*}, r_{e, t}^{*}=M P K_{e, t}^{*}, w_{s, t}^{*}=M P L_{s, t}^{*}$, and $w_{u, t}^{*}=$ $M P L_{u, t}^{*}$. Second, observe that the only budget feasible income strategy for the household is the one that corresponds to some agent's income process in the efficient allocation, i.e. for any history $h^{t}$ in any period $t, y^{t}$ should be in $Y^{t *}$.

Third, we claim that if an agent chooses an income strategy $y^{\prime}$, where this means $y_{t}^{\prime}\left(h^{t}\right)=$ $y_{t}^{*}\left(\hat{h}^{t}\right)$ for some $\hat{h}^{t}$, then the agent also chooses $\left(c^{\prime}, k^{\prime}\right)$ meaning that $c_{t}^{\prime}\left(h^{t}\right)=c_{t}^{*}\left(\hat{h}^{t}\right)$ and $k_{t+1}^{\prime}\left(h^{t}\right)=$ $k_{t+1}^{*}\left(\hat{h}^{t}\right)$, for all $h^{t}, t$. If we can show this claim, then the result that agent will actually choose the efficient allocation follows since efficient allocation is incentive compatible. 
To see this claim, take an agent that follows income strategy $y^{\prime}$. His problem is

$$
\max _{c, k_{s}, k_{e}} \sum_{t=1}^{\infty} \sum_{h^{t} \in H^{t}} \pi_{t}\left(h^{t}\right) \beta^{t-1}\left[u\left(c_{t}\left(h^{t}\right)\right)-v\left(\frac{y_{t}^{*}\left(\hat{h}^{t}\right)}{w_{t}\left(h^{t}\right)}\right)\right]
$$

subject to

$$
\begin{aligned}
& c_{t}\left(h^{t}\right)+k_{s, t+1}\left(h^{t}\right)+k_{e, t+1}\left(h^{t}\right) \leq y_{t}^{*}\left(\hat{h}^{t}\right)-\tau_{t}^{y}\left(y^{t *}\left(\hat{h}^{t}\right)\right) \\
&+\left[1-\tau_{t}^{s}\left(y^{t *}\left(\hat{h}^{t}\right)\right)\right]\left(1-\delta_{s}+r_{s, t}^{*}\right) k_{s, t}\left(h^{t-1}\right) \\
&+\left[1-\tau_{t}^{e}\left(y^{t *}\left(\hat{h}^{t}\right)\right)\right]\left(1-\delta_{e}+r_{e, t}^{*}\right) k_{e, t}\left(h^{t-1}\right), \\
& k_{s, 1} \leq K_{s, 1}^{*}, k_{e, 1} \leq K_{e, 1}^{*}, \\
& c, y, k_{s}, k_{e} \text { is nonnegative. }
\end{aligned}
$$

The FOCs to this problem are the budget constraint holding with equality and

$$
\begin{aligned}
& u^{\prime}\left(c_{t}\left(h^{t}\right)\right)=\left(1-\delta_{s}+r_{s, t+1}^{*}\right) \beta \sum_{h^{t+1} \mid h^{t}} \pi_{t+1}\left(h^{t+1} \mid h^{t}\right) u^{\prime}\left(c_{t+1}\left(h^{t+1}\right)\right)\left[1-\tau_{t+1}^{s}\left(y^{t+1 *}\left(\hat{h}^{t}, h_{t+1}\right)\right],\right. \\
& u^{\prime}\left(c_{t}\left(h^{t}\right)\right)=\left(1-\delta_{e}+r_{e, t+1}^{*}\right) \beta \sum_{h^{t+1} \mid h^{t}} \pi_{t+1}\left(h^{t+1} \mid h^{t}\right) u^{\prime}\left(c_{t+1}\left(h^{t+1}\right)\right)\left[1-\tau_{t+1}^{e}\left(y^{t+1 *}\left(\hat{h}^{t}, h_{t+1}\right)\right] .\right.
\end{aligned}
$$

Clearly, agent's problem is concave and hence these FOCs are necessary and sufficient assuming that $u$ is bounded.

By construction of the labor tax code and the prices, $c_{t}^{*}\left(\hat{h}^{t}\right)$ and $k_{t+1}^{*}\left(\hat{h}^{t}\right)$ satisfy the flow budget constraints. To see that they also satisfy the two Euler equations above, just observe that capital income taxes are constructed such that

$$
1-\tau_{t+1}^{i *}\left(y^{t+1 *}\left(\hat{h}^{t}, h_{t+1}\right)\right)=\frac{u^{\prime}\left(c_{t}^{*}\left(\hat{h}^{t}\right)\right)}{\beta u^{\prime}\left(c_{t+1}^{*}\left(\hat{h}^{t}, h_{t+1}\right)\right)\left(1-\delta_{i}+r_{i, t+1}^{*}\right)} .
$$

\section{Properties of the Optimal Tax System 1.}

1. The tax on capital at the firm level is zero.

2. Taxes on structure capital and equipment capital are different (differential asset taxation), 
and are related to each other according to the following formula:

$$
\left[1-\tau_{t+1}^{e *}\left(y^{t+1}\right)\right]=\frac{F_{1, t+1}^{*}}{F_{2, t+1}^{*}}\left[1-\tau_{t+1}^{s *}\left(y^{t+1}\right)\right]
$$

Observe that this is very similar to how we linked implicit marginal taxes on structure and equipment capitals in Proposition 3. Under Assumptions 4 and 5, this means that in any period $t$, and history $h^{t}$, linear tax rate on equipment capital is higher than that on structure capital.

3. Expected asset income taxes on structure capital are zero as in Kocherlakota (2005). However, expected asset income taxes on equipment capital are strictly positive under Assumptions 4 and 5 .

$$
E_{t}\left\{1-\tau_{t+1}^{s *}\left(y^{t+1}\right)\right\}=E_{t}\left\{\frac{u^{\prime}\left(c_{t}^{*}\left(h^{t}\right)\right)}{\beta u^{\prime}\left(c_{t+1}^{*}\left(h^{t+1}\right)\right) F_{1, t+1}^{*}}\right\}=\frac{1}{F_{1, t+1}^{*}} E_{t}\left\{\frac{u^{\prime}\left(c_{t}^{*}\left(h^{t}\right)\right)}{\beta u^{\prime}\left(c_{t+1}^{*}\left(h^{t+1}\right)\right)}\right\}=1
$$

where the last line follows from Proposition 2 (inverse Euler equation).

$$
E_{t}\left\{1-\tau_{t+1}^{e *}\left(y^{t+1}\right)\right\}=\frac{F_{1, t+1}^{*}}{F_{2, t+1}^{*}} E_{t}\left\{1-\tau_{t+1}^{s *}\left(y^{t+1}\right)\right\}<1
$$

This implies that, unlike in Kocherlakota (2005), the government collects tax revenues through taxing (equipment) capital when there is capital-skill complementarity.

\subsection{Optimal Tax System 2: A Case for Double Taxation of Capital}

This implementation is motivated by the observation that for reasons outside of the scope of this paper it might not be possible to tax the returns from the two types of capital differently. Call the common tax rate on capital $\tau_{t}^{k}\left(y^{t}\left(h^{t}\right)\right)$. We refer to this tax as the wealth tax since it is levied on an agent's total wealth at any history.

Optimal Tax System 2. This tax system is identical to the first one except for two things. First, the previous system taxes the two types of capital at different rates, and this is not allowed in the current system. So, we set wealth taxes such that, for $i=s, e$

$$
\begin{aligned}
\tau_{t+1}^{k *}\left(y^{t+1}\right) & =1-\frac{u^{\prime}\left(c_{t}^{*}\left(h^{t}\right)\right)}{\beta u^{\prime}\left(c_{t+1}^{*}\left(h^{t+1}\right)\right)\left(1-\delta_{s}+r_{s, t+1}\right)}, \text { if } y^{t+1} \in Y^{t+1 *} \\
\tau_{t+1}^{k *}\left(y^{t+1}\right) & =1, \text { if else. }
\end{aligned}
$$


The second difference of this optimal tax system from the first is that there is taxation of equipment capital at the firm level:

$$
\tau_{t}^{f *}=\frac{\tilde{F}_{2, t+1}^{*}}{\tilde{F}_{1, t+1}^{*}-\delta_{s}+\delta_{e}}
$$

Proposition 6. Optimal Tax System 2 implements the efficient allocation.

Proof. We need to show that if an agent chooses an income strategy $y^{\prime}$, where $y_{t}^{\prime}\left(h^{t}\right)=y_{t}^{*}\left(\hat{h}^{t}\right)$ for some $\hat{h}^{t}$, then the agent also chooses $\left(c^{\prime}, k^{\prime}\right)$ meaning that $c_{t}^{\prime}\left(h^{t}\right)=c_{t}^{*}\left(\hat{h}^{t}\right)$ and $k_{t+1}^{\prime}\left(h^{t}\right)=$ $k_{t+1}^{*}\left(\hat{h}^{t}\right)$, for all $h^{t}, t$. The rest of the proof is identical to the proof of Proposition 5 .

To see this, take an agent that follows income strategy $y^{\prime}$. His first-order optimality conditions are the budget constraint holding with equality and

$$
\begin{aligned}
& u^{\prime}\left(c_{t}\left(h^{t}\right)\right)=\left(1-\delta_{s}+r_{s, t+1}^{*}\right) \beta \sum_{h^{t+1} \mid h^{t}} \pi_{t+1}\left(h^{t+1} \mid h^{t}\right) u^{\prime}\left(c_{t+1}\left(h^{t+1}\right)\right)\left[1-\tau_{t+1}^{k}\left(y^{t+1 *}\left(\hat{h}^{t}, h_{t+1}\right)\right],\right. \\
& u^{\prime}\left(c_{t}\left(h^{t}\right)\right)=\left(1-\delta_{e}+r_{e, t+1}^{*}\right) \beta \sum_{h^{t+1} \mid h^{t}} \pi_{t+1}\left(h^{t+1} \mid h^{t}\right) u^{\prime}\left(c_{t+1}\left(h^{t+1}\right)\right)\left[1-\tau_{t+1}^{k}\left(y^{t+1 *}\left(\hat{h}^{t}, h_{t+1}\right)\right] .\right.
\end{aligned}
$$

Clearly, the agent's problem is concave and hence these FOCs are necessary and sufficient assuming that $u$ is bounded.

Observe that these two Euler equations imply that

$$
\left(1-\delta_{s}+r_{s, t+1}^{*}\right)=\left(1-\delta_{e}+r_{e, t+1}^{*}\right)
$$

By construction of the labor tax code, $c_{t}^{*}\left(\hat{h}^{t}\right)$ and $k_{t+1}^{*}\left(\hat{h}^{t}\right)$ satisfy the flow budget constraints. To see that they also satisfy the two Euler Equations above, just observe that capital income taxes are constructed such that

$$
1-\tau_{t+1}^{k *}\left(y^{t+1 *}\left(\hat{h}^{t}, h_{t+1}\right)\right)=\frac{u^{\prime}\left(c_{t}^{*}\left(\hat{h}^{t}\right)\right)}{\beta u^{\prime}\left(c_{t+1}^{*}\left(\hat{h}^{t}, h_{t+1}\right)\right)\left(1-\delta_{s}+r_{s, t+1}^{*}\right)} .
$$

So, facing the right prices, the consumer chooses the efficient allocation. The rental rates come from the optimality conditions of the firm's problem

$$
\begin{aligned}
\tilde{F}_{1}\left(K_{s, t}^{*}, K_{e, t}^{*}, L_{s, t}^{*}, L_{u, t}^{*}\right) & =r_{s, t}^{*} \\
\tilde{F}_{2}\left(K_{s, t}^{*}, K_{e, t}^{*}, L_{s, t}^{*}, L_{u, t}^{*}\right) & =\left(1+\tau_{t}^{f *}\right) r_{e, t}^{*}
\end{aligned}
$$


which implies

$$
\left(1-\delta_{s}+\tilde{F}_{1, t+1}^{*}\right)=\left(1-\delta_{e}+\frac{\tilde{F}_{2, t+1}^{*}}{\left(1+\tau_{t}^{f *}\right)}\right)
$$

which gives $\tau_{t}^{f *}$.

\section{Properties of Optimal Tax System 2.}

1. Capital is taxed twice, once at the consumer level and once at the corporate level (double taxation of capital).

2. The tax on firm's equipment capital payments is strictly positive in the relevant case:

$$
\tau_{t}^{f *}=\frac{\tilde{F}_{2, t+1}^{*}}{\tilde{F}_{1, t+1}^{*}-\delta_{s}+\delta_{e}}>0,
$$

where the inequality comes from Corollary $1 .{ }^{15}$

3. Expected wealth taxes are zero as in Kocherlakota (2010):

$$
\begin{aligned}
E_{t}\left\{1-\tau_{t+1}^{k *}\left(y^{t+1}\right)\right\} & =E_{t}\left\{\frac{u^{\prime}\left(c_{t}^{*}\left(h^{t}\right)\right)}{\beta u^{\prime}\left(c_{t+1}^{*}\left(h^{t+1}\right)\right) F_{1, t+1}^{*}}\right\} \\
& =\frac{1}{F_{1, t+1}^{*}} E_{t}\left\{\frac{u^{\prime}\left(c_{t}^{*}\left(h^{t}\right)\right)}{\beta u^{\prime}\left(c_{t+1}^{*}\left(h^{t+1}\right)\right)}\right\} \\
& =1 .
\end{aligned}
$$

Again, unlike Kocherlakota (2005), government uses taxes on capital to collect tax revenues when there is capital-skill complementarity. Unlike the previous implementation, this collection is done at the firm level and not at the consumer level.

\subsection{Discussion}

We know from Proposition 1 that if there are capital-skill complementarities in the production function it is efficient to create a wedge between the physical marginal returns to structure and equipment capital. The reason is that creating this wedge affects the wage premium in such a way that allows for a higher degree of insurance through taxation. However, in an undistorted incomplete market economy, private agents do not internalize this incentive effect of distorting the structure vs. equipment capital investment margin. Therefore, a benevolent government

\footnotetext{
${ }^{15}$ Note that we tax firm's equipment capital investment only without loss of generality. The government could have instead taxed structure capital investment (which would be a subsidy in the relevant case), or taxed both capital stocks, as long as it creates the efficient capital return wedge.
} 
should intervene to achieve the optimal capital return wedge. In this section, we provided two alternative ways of creating this wedge: either by taxing investment in the two capital types differently at the consumer level (differential asset taxation) or by introducing a tax on at least one of the two capital inputs at the firm level (double taxation of capital). ${ }^{16}$ Indeed, we believe it is possible to prove that if differential asset taxation at the consumer level is not allowed, then double taxation of capital becomes a necessary condition for implementing efficient allocation.

\section{Quantitative Analysis}

In this section, we analyze to what extent the effects discussed theoretically above matter quantitatively. We analyze an environment, in which the sole role of taxation is redistribution. In particular, we assume that skill types are permanent, i.e. they do not change over time. One can think of the initial types as the skill types that agents draw prior to entering the labor market. Once agents enter the labor market, there are no shocks anymore. There is ample empirical evidence that permanent shocks constitute a large part in the cross-sectional variation in wages.

A related exercise has been performed in Werning (2007) who focuses on characterizing the constrained efficient allocation in a standard neoclassical growth model with permanent types. Huggett and Parra (2010) compute the constrained efficient allocation in a partial equilibrium overlapping generations environment. We complement these analyses by taking the capital-skill complementarity into account in an infinite horizon general equilibrium environment. We first characterize the qualitative properties of the constrained efficient allocation. We then solve for the whole sequence of the constrained efficient allocation. In this sense, we refine the results obtained in the above mentioned papers.

Our most important characterization result is that (even) in steady state the equipment capital wedge is positive, while the wedge on structure capital is zero. In our quantitative exercise we first calibrate the model parameters to the U.S. economy using a competitive equilibrium framework with the actual U.S. tax code. We then solve a social planning problem in which the planner 'inherits' the capital levels from the competitive equilibrium. We solve for the whole time series thus taking into account the transition to a new steady state. In line with the theory, we find that the wedge on structure capital should be zero. In contrast, we find that the optimal equipment capital wedge should be positive and increasing from approximately $19.1 \%$ in the first period to $27.5 \%$ in the steady-state. Finally, to assess the welfare gains of differential asset taxation, we solve a planning problem in which the planner is constrained to

\footnotetext{
${ }^{16}$ For a paper on optimality of differential asset taxation and double capital taxation for a class of private information models, see Albanesi (2006).
} 
tax two types of capital as in the data, i.e. tax structure capital more than equipment capital. We find that welfare gains from optimal differential asset taxation are modest at about .04\% of lifetime consumption ( $2 \%$ of annual consumption). Approximately half of these welfare gains can be achieved by switching to a tax system in which both capital types are taxed equally, as recently proposed by the Obama administration.

\subsection{Social Planning Problem with Permanent Types (SPP)}

$$
\begin{gathered}
\max _{c, l, K_{s}, K_{e}} \sum_{j=u, s} p_{j} \sum_{t=1}^{\infty} \beta^{t-1}\left[u\left(c_{t, j}\right)-v\left(l_{t, j}\right)\right] \\
\text { s.t. } \\
\forall t: \sum_{j} p_{j} c_{t, j}+K_{s, t+1}+K_{e, t+1} \leq F\left(K_{s, t}, K_{e, t}, L_{s, t}, L_{u, t}\right), \\
\sum_{t=1}^{\infty} \beta^{t-1}\left[u\left(c_{t, s}\right)-v\left(l_{t, s}\right)\right] \geq \sum_{t=1}^{\infty} \beta^{t-1}\left[u\left(c_{t, u}\right)-v\left(\frac{l_{t, u} w_{t, u}}{w_{t, s}}\right)\right] .
\end{gathered}
$$

We next provide two characterization results (proofs are available upon request).

Proposition 7. The optimal tax on equipment capital is strictly positive in all periods including the steady-state. The optimal tax on structure capital is zero in every period.

Proposition 8. The optimal tax on each capital type is independent of agent type.

\subsection{Competitive Equilibrium with Permanent Types}

In this section, we define a competitive equilibrium with taxes. We use the steady state (stationary equilibrium) of this economy to calibrate the model.

An agent of (permanent) type $i \in\{s, u\}$ and initial asset holdings $a_{i, 0}$ solves

$$
\begin{aligned}
\max _{\left\{c_{i, t}, l_{i, t}, a_{i, t+1}\right\}_{t}} & \sum_{t=1}^{\infty} \beta^{t-1}\left[u\left(c_{i, t}\right)-v\left(l_{i, t}\right)\right] \\
c_{t}^{i}+a_{i, t+1} \leq & w_{i, t} l_{i, t}\left(1-\tau_{l, t}\right)+T_{t}+R_{t} a_{i, t} \\
& a_{i, 0}>0 \text { given } \\
& c_{t}^{i} \geq 0 .
\end{aligned}
$$

Note that in equilibrium non-arbitrage implies that the after-tax returns to investing in two capital types should be the same: $\left[1+\left(r_{s, t}-\delta_{s}\right)\left(1-\tau_{s, t}\right)\right]=\left[1+\left(r_{e, t}-\delta_{e}\right)\left(1-\tau_{e, t}\right)\right] \equiv R_{t}$. We 
further assume that all tax revenue is paid back to the consumers via lump sum transfers, $T_{t}$.

The representative firm's problem in equilibrium gives the wage and interest rates in every period:

$$
r_{s, t}=\frac{\partial \tilde{F}(t)}{\partial K_{s, t}}, \quad r_{e, t}=\frac{\partial \tilde{F}(t)}{\partial K_{e, t}}, \quad w_{s, t}=\frac{\partial \tilde{F}(t)}{\partial L_{s, t}} z_{s}, \quad w_{u, t}=\frac{\partial \tilde{F}(t)}{\partial L_{u, t}} z_{u}
$$

Market clearing conditions are given by:

$$
\sum_{i} p_{i} a_{i, t}=K_{e, t}+K_{s, t}, \quad l_{s, t} p_{s} z_{s}=L_{s, t}, \quad l_{u, t} p_{u} z_{u}=L_{u, t}
$$

Equilibrium. Given a tax system $\left(\tau_{s, t}, \tau_{e, t}, \tau_{l, t}\right)_{t=1}^{\infty}$, a competitive equilibrium is an allocation $\left(c_{s, t}, c_{u, t}, a_{s, t}, a_{u, t}, l_{s, t}, l_{u, t}, K_{s, t}, K_{e, t}, L_{s, t}, L_{u, t}\right)_{t=1}^{\infty}$ and prices $\left(r_{s, t}, r_{e, t}, w_{s, t}, w_{u, t}\right)_{t=1}^{\infty}$ such that $\left(c_{i, t}, a_{i, t}, l_{i, t}\right)_{t=1}^{\infty}$ solves consumer $i / s$ problem, $\left(K_{s, t}, K_{e, t}, L_{s, t}, L_{u, t}\right)_{t=1}^{\infty}$ satisfies pricing conditions, markets for all four production inputs clear, and government budget balances every period:

$$
T_{t}=\left(r_{s, t}-\delta_{s}\right)\left(1-\tau_{s, t}\right) K_{s, t}+\left(r_{e, t}-\delta_{e}\right)\left(1-\tau_{e, t}\right) K_{e, t}
$$

Stationary Competitive Equilibrium (SCE). Given a stationary tax system $\left(\tau_{s}, \tau_{e}, \tau_{l}\right)$, a stationary competitive equilibrium is a stationary allocation $\left(c_{s}, c_{u}, a_{s}, a_{u}, l_{s}, l_{u}, K_{s}, K_{e}, L_{s}, L_{u}\right)$ and prices $\left(r_{s}, r_{e}, w_{s}, w_{u}\right)$ such that $\left(c_{i}, a_{i}, l_{i}\right)$ solves consumer $i / s$ problem, $\left(K_{s}, K_{e}, L_{s}, L_{u}\right)$ satisfies pricing conditions, markets for all four production inputs clear, and government budget balances every period:

$$
T=\left(r_{s}-\delta_{s}\right)\left(1-\tau_{s}\right) K_{s}+\left(r_{e}-\delta_{e}\right)\left(1-\tau_{e}\right) K_{e}
$$

Note that the stationary competitive equilibrium is not unique in this environment. In particular, given aggregate capital levels $K_{s}, K_{e}$ consistent with SCE, any asset distribution of the form $p_{s} a_{s}=\lambda\left(K_{s}+K_{e}\right)$ and $p_{u} a_{u}=(1-\lambda)\left(K_{s}+K_{e}\right)$ with $\lambda \in(0,1)$ can arise in SCE. In our calibration exercise, we pick a $\lambda$ so that the SCE asset distribution matches the observed asset distribution between skilled and unskilled agents in the U.S. data.

\subsection{Parameterization}

To calibrate the parameters in the social planning problem, we assume that the stationary competitive equilibrium represents the current U.S. economy. We first fix a number of parameters. We then calibrate the remaining parameters so that the SCE matches the U.S. data along 
selected dimensions.

We assume that the period utility function takes the form:

$$
u(c)-v(l)=\frac{c^{1-\sigma}}{1-\sigma}-\phi \frac{l^{1+\gamma}}{1+\gamma}
$$

One period in our model corresponds to one year. In the benchmark case, we use $\sigma=2$ and $\gamma=1$. These are within the range of values that have been considered in the literature. We discuss the sensitivity of our results to the choice of the utility function parameters in section 6.6 .

We further assume that the production function takes the form:

$$
Y=F\left(K_{s}, K_{e}, L_{s}, L_{u}\right)=K_{s}^{\alpha}\left(\nu\left[\omega K_{e}^{\rho}+(1-\omega) L_{s}^{\rho}\right]^{\frac{\eta}{\rho}}+(1-\nu) L_{u}^{\eta}\right)^{\frac{1-\alpha}{\eta}}
$$

This is the same functional form as introduced by Krusell, Ohanian, Ríos-Rull, and Violante (2000). It is clear that the derivative of the wage ratio with respect to structure capital $K_{s}$ is zero, i.e. $\frac{\partial\left(\frac{l_{u} w_{u}}{w_{s}}\right)}{\partial K_{s}}=0$. As has been shown above, this implies that the inverse Euler equation is satisfied for the structure capital at the constrained efficient allocation. For equipment capital $K_{e}$ on the other hand, one can show that $\frac{\partial\left(\frac{l_{u} w_{u}}{w_{s}}\right)}{\partial K_{e}}<0 \Longleftrightarrow \eta>\rho$. This is also a condition that is satisfied in empirical papers that estimate capital-skill complementarity. We pick the parameters of the production function from the literature, namely from Greenwood, Hercowitz, and Krusell (1997) and Krusell, Ohanian, Ríos-Rull, and Violante (2000).

As for government policies, we follow Heathcote, Storesletten, and Violante (2010) and assume a flat labor income tax rate $\tau_{l}=0.27$ (for a discussion of the construction of this number, see Domeij and Heathcote (2004)). Gravelle (2011) documents that because of differences in tax depreciation rates, the effective tax rates on structure and equipment capital differ on the firm level. Specifically, the effective tax rate on structure capital is $32 \%$ and the effective tax rate on equipment capital is $26 \%$. We use these values and combine them with the tax rate that consumers pay on capital income $(15 \%)$. This gives us $\tau_{s}=1-.85 \cdot(1-.32)=42.2 \%$ for structure capital and $\tau_{e}=1-.85 \cdot(1-.26)=37.2 \%$ for equipment capital. Note that these numbers are consistent with a $40 \%$ tax which Domeij and Heathcote (2004) report for the aggregate capital stock. We set the ratio of skilled to unskilled agents to be consistent with US Census data. As discussed above, we need to select among the non-unique stationary competitive equilibria. We select the one in which the ratio of wealth of skilled to unskilled agents is consistent with US Census data. Table 1 summarizes our benchmark parameters.

This leaves us with several parameters to be determined. We cannot identify $z_{u}$ and $z_{s}$ separately from the remaining parameters of the production function and therefore set them to 
Table 1: Benchmark Parameters in the Incomplete Markets Model

\begin{tabular}{|c|c|c|c|}
\hline Parameter & Symbol & Value & Source \\
\hline Relative risk aversion wrt consumption & $\sigma$ & 1 & \\
\hline Inverse Frisch elasticity & $\gamma$ & 1 & \\
\hline Structure capital depreciation rate & $\delta_{s}$ & 0.056 & GHK \\
\hline Equipment capital depreciation rate & $\delta_{e}$ & 0.124 & GHK \\
\hline Share of structure capital in output & $\alpha$ & 0.117 & KORV \\
\hline $\begin{array}{l}\text { Measure of elasticity of substitution between } \\
\text { equipment capital } K_{e} \text { and unskilled labor } L_{u} \\
\text { Measure of elasticity of substitution between }\end{array}$ & $\eta$ & 0.401 & $\mathrm{KORV}$ \\
\hline equipment capital $K_{e}$ and skilled labor $L_{s}$ & $\rho$ & -0.495 & KORV and He and Liu (2008) \\
\hline Tax on labor income & $\tau_{l}$ & 0.27 & HSV \\
\hline Tax on structure capital income & $\tau_{s}$ & 0.422 & Gravelle (2011) \\
\hline Tax on equipment capital income & $\tau_{e}$ & 0.371 & Gravelle (2011) \\
\hline Relative supply of skilled workers & $p_{s} / p_{u}$ & $77.8 \%$ & U.S. Census Bureau \\
\hline Relative wealth of skilled workers & & 2.680 & U.S. Census Bureau \\
\hline
\end{tabular}

The acronyms GHK and KORV stand for Greenwood, Hercowitz, and Krusell (1997) and Krusell, Ohanian, Ríos-Rull, and Violante (2000), respectively. HSV stands for Heathcote, Storesletten, and Violante (2010). Duffy, Papageorgiou, and Perez-Sebastian (2004) reports a different value for $\eta$ than KORV, namely 0.79. This number has been used e.g. in He and Liu (2008). We analyze to what extent our results depend on the choice of this value in section 6.6 .

Table 2: Benchmark Calibration Procedure

\begin{tabular}{cc||cc} 
Parameter & Value & Target & Value in Data and SCE \\
\hline \hline Discount factor $\beta$ & 0.9796 & Capital to output ratio & 2.65 \\
Disutility of labor $\phi$ & 40.6105 & Labor supply & $1 / 3$ \\
Income share of equipment capital $\omega$ & 0.4499 & Labor share & $2 / 3$ \\
1 - income share of unskilled labor $\nu$ & 0.6708 & Skill premium & $80 \%$
\end{tabular}

$z_{u}=z_{s}=1$. We then calibrate $\omega$ (the income share of equipment capital), $\nu$ (1- income share of unskilled labor), the labor disutility parameter $\phi$ and the discount factor $\beta$. We calibrate these parameters so that the aggregate labor supply in steady state equals $1 / 3$, the skill premium equals $80 \%$ (as reported by Heathcote, Perri, and Violante (2010) for the 2000's), labor share equals $2 / 3$ and the capital to output ration equals 2.65. Table 2 summarizes the calibration procedure.

\subsection{Benchmark Numerical Results}

In this section, we report the properties of the solution to the social planning problem with permanent types, in which we use the parameters calibrated in the competitive equilibrium 
economy. ${ }^{17}$

We find that the intertemporal wedge on equipment capital defined in section 4 is positive in all periods in line with proposition 7. In contrast, the wedge on structure capital is zero in each period as shown in proposition 7 as well. Figures 1 and 2 summarize the rest of our results. In figure 1 we report the evolution of the equipment to structure capital ratio along with an alternative intertemporal wedge on equipment capital. The alternative intertemporal wedge coincides with capital income taxes used in practice as in Golosov, Troshkin, Tsyvinski, and Weinzierl (2010). Similarly to U.S. tax code we allow for a depreciation allowance. These implicit capital income tax rates for the two types of capital can be recovered from the appropriate Euler equations and for each history $j^{t}, j \in\{u, s\}$ they are defined as:

$$
\begin{aligned}
& \text { alt } \tau_{K, s}\left(j^{t}\right)=1-\frac{\frac{u^{\prime}\left(c_{t, j}\right)}{\beta u^{\prime}\left(c_{t+1, j}\right)}-1}{\tilde{F}_{K_{s, t+1}}-\delta_{s}} \\
& \text { alt } \tau_{K, e}\left(j^{t}\right)=1-\frac{u^{\prime}\left(c_{t, j}\right)}{\beta u^{\prime}\left(c_{t+1, j}\right)}-1 \\
& \tilde{F}_{K_{e, t+1}}-\delta_{e}
\end{aligned}
$$

By corollary to proposition 8 these wedges only depend on time and not on agent type; therefore we only plot one time series. We find, that the equipment capital wedge is substantial and increasing over time. In steady state it is $27.45 \%$, i.e. $27.45 \%$ higher that the wedge on structure capital, which is zero. This is in contrast with the effective tax rates in the U.S. where structure capital is taxed by $5.10 \%$ more than equipment capital, as discussed in more detail above. The equipment to structure capital ratio decreases, which is in line with the evolution of the wedges.

By taxing equipment capital more, the planner indirectly redistributes from the high skilled to the low skilled by decreasing the skill premium (the wage ratio $\frac{w_{s}}{w_{u}}$ ). This can be seen in the second panel of figure 1. Here, the skill premium increases over time somewhat, but it is much smaller than in the data and our calibrated competitive equilibrium benchmark, in which the skill premium equals 1.8 .

The other channel for indirect redistribution is a marginal subsidy for the skilled workers. The subsidy increases their labor supply decreasing the skill premium. As we see in the first panel of figure 2, the planner subsidizes skilled labor with a subsidy of around 10\% while taxing low skilled types with a tax of slightly below 25\%. These taxes are lower than in the data inducing in particular the skilled agents to work more (recall that we calibrated the model so that aggregate labor supply equals $1 / 3)$.

\footnotetext{
${ }^{17}$ We solve the social planning problem by assuming that the economy converges to a steady state in 200 periods. We verify that changing the number of periods does not affect the results. In other words, the economy converges to steady state long before period 200.
} 
Figure 1: Equipment Capital Wedges and Capital Ratio in Second Best
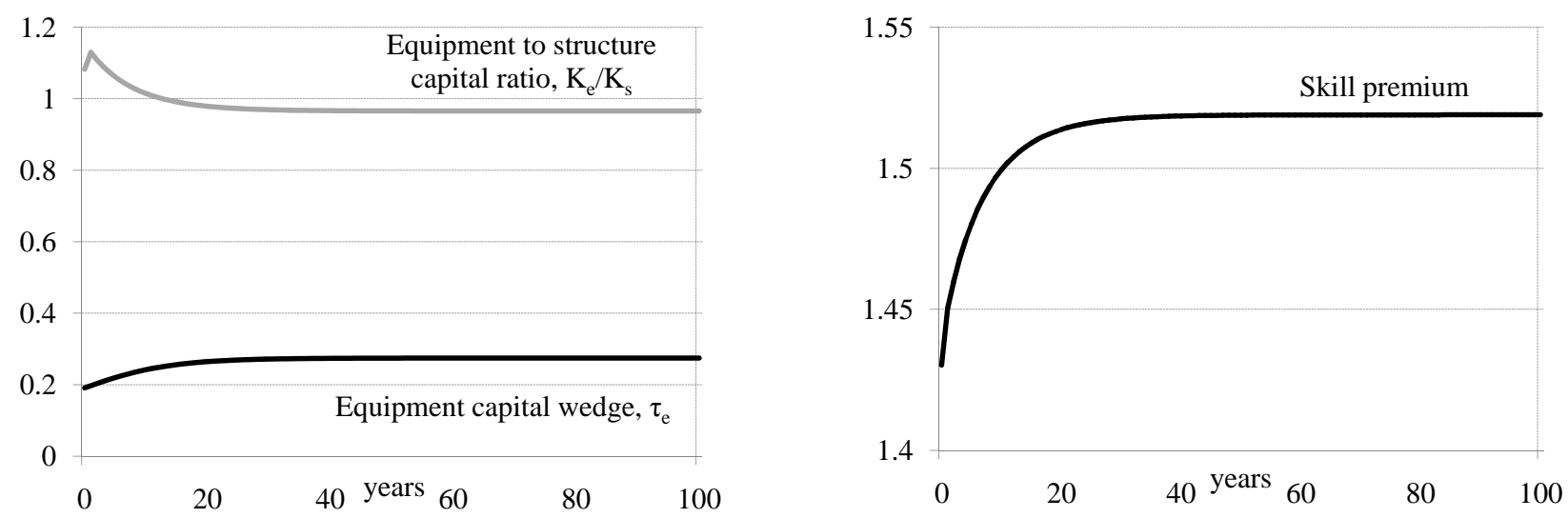

Figure 2: Labor Wedges and Labor Supplies in Second Best
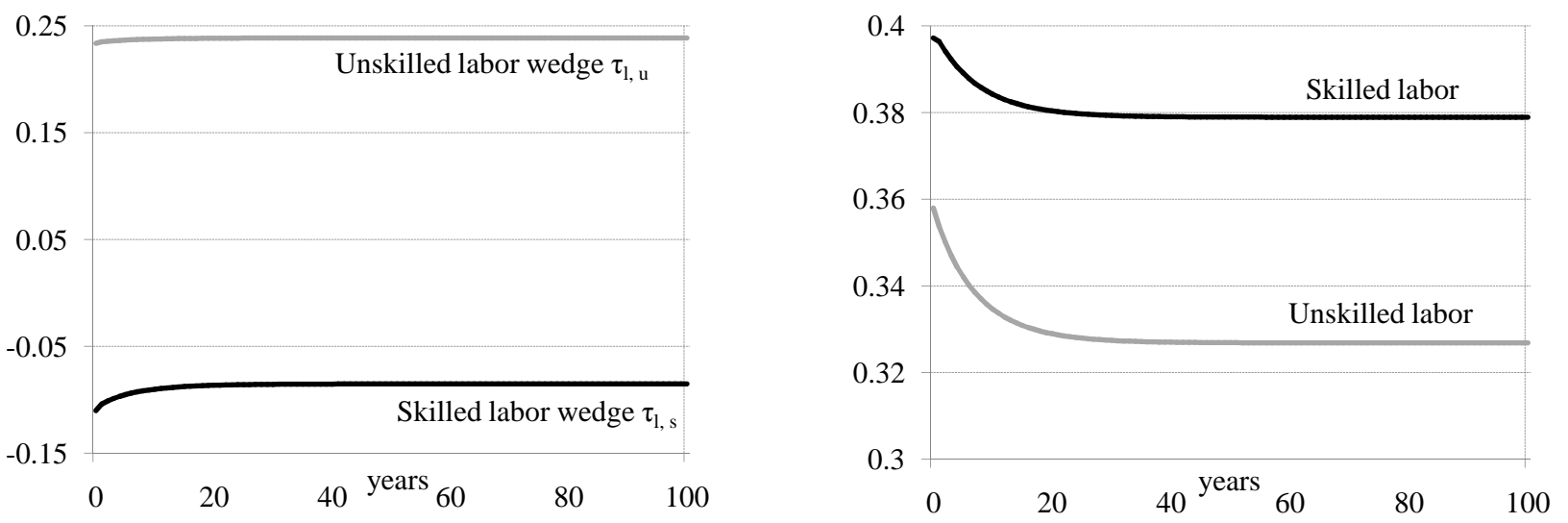


\subsection{Welfare Gains of Differential Capital Taxation}

To assess the quantitative importance of differential capital taxation we solve two additional versions of the social planning problem. In the first we restrict the set of allocations that the planner can choose from to allocations that feature the same capital return wedge as the stationary competitive equilibrium (SCE) with the current U.S. capital income taxes. It is straightforward to show that the capital return wedge in SCE equals

$$
\tau_{E}(t):=\frac{F_{K_{e, t}}}{F_{K_{s, t}}}-1=\frac{1-\tau_{s}}{1-\tau_{e}} \cdot \frac{1-\tau_{e}+(1-\beta) / \beta}{1-\tau_{s}+(1-\beta) / \beta}-1
$$

We impose this constraint in each period. This way, the planner implements the same distortions in the capital taxes as those in the U.S. economy. We call the allocation that solves this problem "current distortions allocation."

The second version of the social planning problem we solve corresponds to the proposals of the Obama administration to equalize the effective capital tax rates. We restrict the social planner to choose from allocations with the same wedge for equipment and structure capital, i.e. we impose that that for any history $h^{t}$

$\tau_{K, s}\left(h^{t}\right):=1-\frac{u^{\prime}\left(c_{t}\left(h^{t}\right)\right)}{\beta F_{s, t+1} E_{t}\left\{u^{\prime}\left(c_{t+1}\left(h^{t+1}\right)\right) \mid h^{t}\right\}}=1-\frac{u^{\prime}\left(c_{t}\left(h^{t}\right)\right)}{\beta F_{e, t+1} E_{t}\left\{u^{\prime}\left(c_{t+1}\left(h^{t+1}\right)\right) \mid h^{t}\right\}}=: \tau_{K, e}\left(h^{t}\right)$

This condition can be simplified to an equality constraint on net returns: $\tilde{F}_{s, t+1}-$ delta $a_{s}=$ $F_{e, t+1}-\delta_{e}$, which we impose for each period. This means that both the standard as well as the alternative wedge are equal for the two types of capital. Effectively, the planner is choosing the best allocation from those that feature equal capital taxes for equipment and structure capital. We call the allocation that solves this problem the "equal taxation allocation."

We then evaluate the welfare gains of the "equal taxation allocation" relative to the "current distortions allocation." In addition, we evaluate the welfare improvement associated with the efficient allocation that solve the SPP defined earlier. We measure the welfare gains as a fraction by which the consumption in the "current distortions allocation" in each date and state would have to be increased in order to make the welfare of the "equal taxation allocation" (or efficient allocation) equal to the welfare level attained by the planning allocation. We keep the labor allocation unchanged. Note that the efficient allocation must feature higher welfare than the other two, but the welfare ranking of "current distortions allocation" and the "equal taxation allocation" is not clear a priori.

We find that the "equal taxation allocation" improves welfare relative to the "current distortions allocation". The welfare improvement is intuitive given that the "equal taxation allocation" 
features higher implicit taxes on structure capital than on equipment capital, contrary to the efficient allocation. The "equal taxation allocation" gets closer to the efficient allocation by equalizing the implicit taxes and thus reduces the welfare loss. The welfare improvement is modest at . $0187 \%$ in terms of lifetime consumption (this roughly corresponds to $1 \%$ in terms of annual consumption).

The welfare gains of the efficient allocation relative to the "current distortions allocation" are again modest at .0411\% in terms of lifetime consumption (this roughly corresponds to $2 \%$ in terms of annual consumption). Interestingly, the welfare gain of going all the way to the efficient allocation are about twice as large as those associated with the Obama administration proposals.

The fact that the welfare gains are modest is probably related to the fact that the planner is otherwise free in his instruments. Specifically, he can use any labor taxes and lump sum taxes and these seem to be sufficient to provide a close to optimal level of redistribution. In other words, the planner does not need to have access to differential capital taxation for redistribution purposes. In addition, the sole reason for taxation in our environment is redistribution. because there are no shocks, there is no need to use taxation to provide insurance.

It would be interesting to analyze the welfare consequences of differential capital taxation in an environment in which the rest of the tax code corresponds to reality and agents face earnings uncertainty. We suspect that the welfare gains might be substantially larger. This issue remains a topic for future research.

\subsection{Additional Quantitative Results}

To be added.

\section{Conclusion}

To be added. 


\section{References}

Acemoglu, D. (1998): "Why Do New Technologies Complement Skills? Directed Technical Change And Wage Inequality," The Quarterly Journal of Economics, 113(4), 1055-1089.

Albanesi, S. (2006): "Optimal Taxation of Entrepreneurial Capital with Private Information," CEPR Discussion Papers 5647, C.E.P.R. Discussion Papers.

Atkinson, A. B., And J. E. Stiglitz (1976): "The design of tax structure: Direct versus indirect taxation," Journal of Public Economics, 6(1-2), 55-75.

DomeiJ, D., and J. Heathcote (2004): "On The Distributional Effects Of Reducing Capital Taxes," International Economic Review, 45(2), 523-554.

Duffy, J., C. Papageorgiou, and F. Perez-Sebastian (2004): "Capital-Skill Complementarity? Evidence from a Panel of Countries," Review of Economics and Statistics, 86(1), $327-344$.

FArhi, E., And I. Werning (2012): "Insurance and Taxation over the Lifecycle," NBER Working Paper Series 16749.

Fernandes, A., And C. Phelan (2000): "A Recursive Formulation for Repeated Agency with History Dependence," Journal of Economic Theory, 91(2), 223-247.

Golosov, M., N. Kocherlakota, and A. Tsyvinski (2003): "Optimal Indirect and Capital Taxation," Review of Economic Studies, 70(3), 569-587.

Golosov, M., M. Troshkin, and A. Tsyvinski (2011): “Optimal Dynamic Taxes," NBER Working Papers 17642, National Bureau of Economic Research, Inc.

Golosov, M., M. Troshkin, A. Tsyvinski, and M. Weinzierl (2010): "Preference Heterogeneity and Optimal Capital Income Taxation," NBER Working Papers 16619, National Bureau of Economic Research, Inc.

Gravelle, J. G. (1994): The Economic Effects of Taxing Capital Income. Massachusetts Institute of Technology Press, Cambridge, MA.

- (2011): "Reducing Depreciation Allowances to Finance a Lower Corporate Tax Rate," National Tax Journal, 64(4), 1039-1054.

Green, E. (1987): "Lending and the smoothing of uninsurable income," in Contractual Arrangements for Intertemporal Trade, vol. 1 of Minnesota Studies in Macroeconomics series. Minneapolis: University of Minnesota Press. 
Greenwood, J., Z. Hercowitz, and P. Krusell (1997): "Long-Run Implications of Investment-Specific Technological Change," American Economic Review, 87(3), 342-62.

Grochulski, B., and T. Piskorski (2010): "Risky human capital and deferred capital income taxation," Journal of Economic Theory, 145(3), 908-943.

He, H., And Z. LiU (2008): "Investment-Specific Technological Change, Skill Accumulation, and Wage Inequality," Review of Economic Dynamics, 11(2), 314-334.

Heathcote, J., F. Perri, and G. L. Violante (2010): "Unequal We Stand: An Empirical Analysis of Economic Inequality in the United States: 1967-2006," Review of Economic Dynamics, 13(1), 15-51.

Heathcote, J., K. Storesletten, and G. L. Violante (2010): "The Macroeconomic Implications of Rising Wage Inequality in the United States," Journal of Political Economy, 118(4), 681-722.

Huggett, M., and J. C. Parra (2010): "How Well Does the U.S. Social Insurance System Provide Social Insurance?," Journal of Political Economy, 118(1), 76-112.

Kocherlakota, N. (2010): The New Dynamic Public Finance, The Toulouse Lectures in Economics. Princeton University Press, ISBN: 9780691139159.

Kocherlakota, N. R. (2005): "Zero Expected Wealth Taxes: A Mirrlees Approach to Dynamic Optimal Taxation," Econometrica, 73(5), 1587-1621.

Krusell, P., L. E. Ohanian, J.-V. Ríos-Rull, and G. L. Violante (2000): "CapitalSkill Complementarity and Inequality: A Macroeconomic Analysis," Econometrica, 68(5), 1029-1054.

MirrleEs, J. A. (1971): "An Exploration in the Theory of Optimum Income Taxation," Review of Economic Studies, 38(114), 175-208.

Naito, H. (1999): "Re-examination of uniform commodity taxes under a non-linear income tax system and its implication for production efficiency," Journal of Public Economics, 71(2), $165-188$.

Rogerson, W. P. (1985): "Repeated Moral Hazard," Econometrica, 53(1), 69-76.

Rotschild, C., And F. Scheuer (2012): "Redistributive Taxation in a Roy Model," Working paper. 
SADKA, E. (1976): "On Income Distribution, Incentive Effects and Optimal Income Taxation," Review of Economic Studies, 43(2), 261-67.

SEAdE, J. K. (1977): "On the shape of optimal tax schedules," Journal of Public Economics, $7(2), 203-235$.

Stiglitz, J. E. (1982): "Self-selection and Pareto efficient taxation," Journal of Public Economics, $17(2), 213-240$.

Violante, G. L. (2008): "Skill-Biased Technical Change," The New Palgrave Dictionary of Economics, Second Edition.

Werning, I. (2007): "Optimal Fiscal Policy with Redistribution," The Quarterly Journal of Economics, 122(3), 925-967. 


\section{Appendix}

\section{A Differences in Capital Prices}

In this subsection we allow for a deterministic change in the relative price of equipment capital and analyze how that affects intertemporal wedges. We show that the results of section 4 carry over with only slight modifications. Letting $q_{t}$ be the period $t$ price of equipment capital in terms of period $t$ consumption good, the resource constraint becomes:

$$
\sum_{h^{t} \in H^{t}} \pi_{t}\left(h^{t}\right) c_{t}\left(h^{t}\right)+K_{s, t+1}+q_{t} K_{e, t+1} \leq \tilde{F}\left(K_{s, t}, K_{e, t}, L_{s, t}, L_{u, t}\right)+\left(1-\delta_{s}\right) K_{s, t}+\left(1-\delta_{e}\right) K_{e, t} q_{t} .
$$

This is the only modification in the planning problem. The next proposition summarizes the adjustments required in proposition 1 and proposition 2 and the respective corollaries (note that the results of section 4.3 go through as well).

\section{Proposition 9.}

1. The capital return wedge is given by

$$
\tilde{F}_{1, t+1}^{*}+1-\delta_{s}=\tilde{F}_{2, t+1}^{*}+\left(1-\delta_{e}\right) q_{t+1} / q_{t}+X_{t+1}^{*} /\left(\lambda_{t+1} q_{t}\right)
$$

2. The capital return wedge is given by

$$
\tau_{E}^{*}(t)=\frac{\tilde{F}_{2, t+1}^{*}+\left(1-\delta_{e}\right) q_{t+1} / q_{t}}{\tilde{F}_{2, t+1}^{*}+\left(1-\delta_{e}\right) q_{t+1} / q_{t}+X_{t+1}^{*} /\left(\lambda_{t+1} q_{t}\right)}-1
$$

3. The optimality condition for $K_{s}$ is given by proposition 2 and for $K_{e}$ by

$$
\frac{1}{u^{\prime}\left(c_{t}^{*}\left(h^{t}\right)\right)}=\frac{1}{\beta\left[\tilde{F}_{2, t+1}^{*}+\left(1-\delta_{e}\right) q_{t+1} / q_{t}+X_{t+1}^{*} /\left(\lambda_{t+1} q_{t}\right)\right]} E_{t}\left\{\frac{1}{u^{\prime}\left(c_{t+1}^{*}\left(h^{t+1}\right)\right)} \mid h^{t}\right\} .
$$

4. The implicit tax on $K_{s}$ is given by corollary 2 and on $K_{e}$ by

$$
\left[1-\tau_{e}^{\text {inter }}\left(h^{t}\right)\right]=\frac{\left[F_{2, t+1}^{*}+\left(1-\delta_{e}\right) q_{t+1} / q_{t}+X_{t+1}^{*} /\left(\lambda_{t+1} q_{t}\right)\right]}{F_{2, t+1}^{*}}\left[1-\tau_{s}^{\text {inter }}\left(h^{t}\right)\right] .
$$

